\title{
Myoglobin variants are expressed in human glioblastoma cells-hypoxia effect?
}

\author{
RANA EL-TOHAMY ${ }^{1}$, ISLAM ELKHOLI ${ }^{1-3}$, MARWA E. ELSHERBINY $^{4}$, MONA MAGDY ${ }^{5}$, \\ OLFAT HAMMAM $^{5}$, JOAN ALLALUNIS-TURNER ${ }^{6}$ and MARWAN EMARA ${ }^{1}$ \\ ${ }^{1}$ Center for Aging and Associated Diseases, Helmy Institute for Medical Sciences, \\ Zewail City of Science and Technology, Giza 12578, Egypt; ${ }^{2}$ Montreal Clinical Research Institute (IRCM), \\ Montréal, QC H2W 1R7; ${ }^{3}$ Molecular Biology Programs, Université de Montréal, Montréal, QC H3T 1J4, Canada; \\ ${ }^{4}$ Department of Pharmacology and Toxicology, Ahram Canadian University, 6th of October City, Giza 12566; \\ ${ }^{5}$ Department of Pathology, Theodor Bilharz Research Institute (TBRI), Imbaba, Giza 12411, Egypt; \\ ${ }^{6}$ Department of Oncology, University of Alberta and Alberta Health Services, Cross Cancer Institute, \\ Edmonton, AB T6G 1Z2, Canada
}

Received June 11, 2019; Accepted December 5, 2019

DOI: $10.3892 /$ or.2020.7479

\begin{abstract}
Glioblastoma multiforme (GBM) is the most aggressive human brain cancer. Little is known regarding how these cells adapt to the harsh tumor microenvironment, and consequently survive and resist various treatments. Myoglobin (MB), the oxygen-binding hemoprotein, has been shown to be ectopically expressed in different human cancers and cell lines, and its expression is hypothesized to be an adaptation mechanism to hypoxia. The aim of the present study was to determine whether cancer-related and hypoxia-responsive MB mRNA splice variants are expressed in human GBM cells and glioblastoma tumor xenografts, and whether their expression is induced by hypoxia and correlated with hypoxia markers [lactate dehydrogenase A (LDHA), glucose transporter 1 (GLUT1), vascular endothelial growth factor (VEGF) and carbonic anhydrase IX (CAIX)]. Conventional reverse transcription (RT)-PCR, DNA sequencing, RT-quantitative PCR and immunohistochemistry were conducted to investigate $\mathrm{MB}$ expression in hypoxia-sensitive (M010b, M059J) and -tolerant (M059K, M006xLo) GBM cell lines that also exhibit differential response towards radiation, rendering them a valuable translational GBM model. It was revealed that cancer-related $\mathrm{MB}$ variants 9, 10, 11 and 13 were expressed in GBM cells under normoxia, and following hypoxia, their expression exhibited modest-to-significant upregulation
\end{abstract}

Correspondence to: Dr Marwan Emara, Center for Aging and Associated Diseases, Helmy Institute for Medical Sciences, Zewail City of Science and Technology, Ahmed Zewail Road, October Gardens, 6th of October City, Giza 12578, Egypt

E-mail: memara@zewailcity.edu.eg

Key words: glioblastoma multiforme, myoglobin, lactate dehydrogenase A, glucose transporter 1, vascular endothelial growth factor, carbonic anhydrase IX that correlated with hypoxia markers. It was also demonstrated that MB was upregulated in hypoxic microregions of glioblastoma tumor xenografts that were stained in matched tumor regions of serial tumor sections with the hypoxia markers, pimonidazole, CAIX, VEGF and LDHA. The present study identified myoglobin as a potential contributor to the hypoxia adaptation and survival strategies of glioblastoma, and may explain the aggressiveness and frequent recurrence rates associated with GBM.

\section{Introduction}

Glioblastoma multiforme (GBM) is the most common primary brain cancer and is associated with dismal prognosis, with reported 2- and 5-year survival rates of 26-33 and 4-5\%, respectively (1). Pathognomonic features of GBM include the presence of microvascular proliferation and necrosis (2), both indicative of hypoxia. As hypoxic cancer cells are genetically unstable and metastasize frequently, defensive mechanisms responsible for cancer cell survival under hypoxia could shed the light on factors responsible for tumor aggressiveness and recurrence $(3,4)$. Previous studies have shown that GBM biopsy- and xenograft-derived cell lines exhibit regional variation in oxygen consumption (5-7). Using cell lines from hypoxia-sensitive and hypoxia-tolerant GBM cells, substantial differences in their responses to hypoxia were observed; the hypoxia-tolerant cell lines (M006x and M059K) significantly reduced their oxygen consumption rates and maintained their clonogenic potential after 4 days of hypoxia ( $0.6 \%$ oxygen), whereas the hypoxia-sensitive cells (M010b) failed to reduce their oxygen consumption rates or to maintain their clonogenic potential (5). Additional studies (3,8-11) also suggest that understanding the molecular mechanism underlying the adaptation of GBM cells or cross-talk with the hypoxic microenvironment can lead to defining novel therapeutic modalities.

The heme family of proteins includes myoglobin (MB), neuroglobin $(\mathrm{Ngb})$, hemoglobin $(\mathrm{Hb})$ and cytoglobin (Cygb). 
The monomeric oxygen-binding hemoprotein MB was the first protein with a determined three-dimensional molecular structure to be reported (12). Despite the fact that MB is one of the most studied proteins (13), its physiological functions in normal and cancer cells remain to be fully explored. Although MB was previously considered to be expressed exclusively in cardiac and skeletal muscle of vertebrates (14), its expression has been reported in human smooth muscles (15), non-muscle cells (liver, brain and gills) of hypoxia-tolerant common carp and goldfish $(16,17)$, normal human (breast, colon, head and neck) tissues $(18,19)$, and different human cancers and cancer cells (18-26). More notably, following extensive systemic research studies on the human MB gene structure, transcripts and promoters, Bicker et al (19) reported 16 novel alternatively spliced variants predominantly expressed in cancer tissue or cell lines, in addition to the three previously annotated ones. Out of 19 transcript variants, nine encode the standard MB protein found in muscle. In contrast to the standard MB transcript variant 2 (muscle transcript, NM_005368.2) (27), the alternative protein-coding cancer-associated MB splice variants 9,10, 11 and 13 (NM_203377.1) are hypoxia-inducible, transcribed from an alternate predicted promoter different from the one used by variant $2(20,21,27)$. However, whether these MB splice variants are expressed or regulated by hypoxia in GBM cells has not been investigated.

Our previous studies reported that $\mathrm{Ngb}, \mathrm{Cygb}$, and $\mathrm{Hb}(\alpha, \beta, \gamma, \delta, \zeta$ and $\varepsilon)$ are expressed in human GBM cell lines, human GBM tissue microarrays and different tissue tumors (3,8-11); thus, it was hypothesized that MB may be similarly expressed. In the present study, it was investigated as to whether MB coding splice variants $(2,9,10,11$ and 13) and protein are expressed in GBM cell lines (hypoxia-sensitive and hypoxia-tolerant) and GBM tumor xenografts, respectively, and whether their expression correlates with the hypoxia markers lactate dehydrogenase A (LDHA), glucose transporter 1 (GLUT1), vascular endothelial growth factor (VEGF) and carbonic anhydrase IX (CAIX) under hypoxia.

\section{Materials and methods}

Cell lines and in vitro culture conditions. The cell lines used in the study were previously established in-house from diagnostic biopsies obtained from patients with diagnoses of GBM; details of their establishment and characterization have been published previously $(7,28)$. M059J and M010b cell lines are hypoxia-sensitive (29,30); M059K and M006xLo cell lines are hypoxia-tolerant $(5,31)$. All cells were maintained as monolayer cultures in DMEM/F12 media (Lonza Group, Ltd.) supplemented with $10 \%$ fetal bovine serum (cat. no. 10270106; Gibco; Thermo Fisher Scientific, Inc.) in a humidified atmosphere of $5 \% \mathrm{CO}_{2}$ at $37^{\circ} \mathrm{C}$. All tissue culture plasticwares were obtained from Greiner Bio-One.

$R N A$ extraction and reverse transcription $(R T)$. An RNeasy Plus Mini Kit with gDNA Eliminator Spin Columns (cat. no. 74136; Qiagen, Inc.) was used to isolate total RNA from GBM cell lines. RT was conducted with $2 \mu \mathrm{g}$ total RNA per $20 \mu \mathrm{l}$ reaction volume using a high-capacity cDNA Reverse Transcription Kit (cat. no. 4368814; Applied Biosystems; Thermo Fisher Scientific, Inc.) with RNase
Inhibitor (cat. no. N8080119; Applied Biosystems; Thermo Fisher Scientific, Inc.).

$R T-P C R$. RT-PCR was conducted with RNA from the M006xLo cell line using a Veriti ${ }^{\mathrm{TM}}$ Thermal Cycler (Applied Biosystems; Thermo Fisher Scientific, Inc.) using Platinum Pfx DNA polymerase (cat. no. 11708-021; Invitrogen; Thermo Fisher Scientific, Inc.) for 40 cycles. Oligonucleotide primer pairs (Integrated DNA Technologies, Inc.) for three previously annotated MB variants [variant 2 (NM_005368.2), variant 5 (NM_203378.1) and variant 13 (NM_203377.1); formerly variants 1, 2 and 3, respectively] $(26,27,32)$, as well as for the novel variants 2 (muscle transcript, NM_005368.2), 9, 10, 11 and 13 (NM_203377.1) $(19,21)$ were used (Table SI). The template DNA was initially denatured for $5 \mathrm{~min}$ at $94^{\circ} \mathrm{C}$, and each cycle of PCR amplification was conducted as follows: Denaturation for $15 \mathrm{sec}$ at $94^{\circ} \mathrm{C}$, annealing [different annealing temperature was used for each variant (Table SI)] for $30 \mathrm{sec}$ and extension for $1 \mathrm{~min}$ at $68^{\circ} \mathrm{C}$. A final extension was carried out for $5 \mathrm{~min}$ at $68^{\circ} \mathrm{C}$, and then the reaction was maintained at $4^{\circ} \mathrm{C}$. Amplified RT-PCR products along with a DNA ladder (1 Kb Plus DNA ladder; cat. no. 10787026; Invitrogen; Thermo Fisher Scientific, Inc.) were separated on 2\% agarose (cat. no. BP1356-500; Fisher Scientific; Thermo Fisher Scientific, Inc.) gels and visualized by ethidium bromide (cat. no. E/P800/10; Fisher Scientific; Thermo Fisher Scientific, Inc.).

DNA sequencing. Bands of RT-PCR amplicons were excised from the agarose gel and purified using a MinElute ${ }^{\circledR}$ Gel Extraction Kit (cat. no. 28604; Qiagen, Inc.). The purified PCR products were sequenced at Colors Medical Laboratories using a 3500 Genetic Analyzer (Applied Biosystems; Thermo Fisher Scientific, Inc.). Sequencing data were analyzed using the National Center for Biotechnology Information (NCBI) Basic Local Alignment Search Tool (BLAST; version 4) engine (33).

Generation of hypoxia in vitro. To study the effect of hypoxia on the protein-coding MB mRNA variants compared with hypoxia markers, hypoxia-sensitive and hypoxia-tolerant cell lines were incubated under moderate hypoxic conditions that simulate the brain tumor microenvironment. Generation of hypoxia in vitro was conducted as previously described with modifications $(9,34)$, with a hypoxia chamber (Biospherix, Ltd.) connected to a ProOx C21 controller unit (Biospherix, Ltd.) to control the levels of $\mathrm{O}_{2}$ and $\mathrm{CO}_{2}$ inside the hypoxia chamber. Cells $\left(\sim 4 \times 10^{5}\right)$ in the exponential phase of growth were seeded onto $100-\mathrm{mm}$ tissue culture dishes and then incubated at $37^{\circ} \mathrm{C}$ under standard laboratory culture conditions $\left(5 \% \mathrm{CO}_{2}\right.$ in air). Then, 2 days later, cells of each cell line were incubated under hypoxia $\left(0.6 \%\right.$ oxygen and $5 \% \mathrm{CO}_{2}$ ) for 12,24 or $48 \mathrm{~h}$ with no media change during the course of the experiment. The aerobic control of each cell line was incubated under normoxic conditions in the standard $\mathrm{CO}_{2}$ incubator. Four replicate experiments were carried out for each cell line.

RT-quantitative PCR ( $q P C R)$. RT-qPCR analysis was performed with a Quant Studio 12K Flex Real-Time PCR System (Applied Biosystems; Thermo Fisher Scientific, Inc.). TaqMan $^{\mathrm{TM}}$ Fast Universal PCR Master Mix (cat. no. 4366072; Applied Biosystems; Thermo Fisher Scientific, Inc.) and 
validated TaqMan Gene Expression Assays (Applied Biosystems; Thermo Fisher Scientific, Inc.) were used for human LDHA (assay no. Hs01378790_g1), GLUT1 (assay no. Hs00892681_m1), VEGF (assay no. Hs00900055 m1), CAIX (assay no. Hs00154208_m1) and $\beta$-actin (cat. no. 4333762F). Primers (Integrated DNA Technologies, Inc.) for protein-coding MB mRNA variants 2, 9, 10, 11 and 13 (19-21) and $\beta$-actin (Table SII) were mixed with Power-Up ${ }^{\mathrm{TM}}$ SYBR $^{\mathrm{TM}}$ Green Master Mix (cat. no. A25778; Applied Biosystems; Thermo Fisher Scientific, Inc.) and qPCR was conducted as previously described (19-21). The relative fold change in mRNA of target genes for each cell line was calculated from four experimental replicates (four different passages) in duplicate assays. In each experimental replica, the mean quantification cycle $(\mathrm{Cq})$ of the endogenous housekeeping gene ( $\beta$-actin) was subtracted from the mean $\mathrm{Cq}$ of the target gene for aerobic controls, and cells treated with hypoxia for 12,24 and $48 \mathrm{~h}$. Then, the resulting value $(\Delta \mathrm{Cq})$ of the aerobic control was subtracted from itself and from the resulting values $(\Delta \mathrm{Cq})$ of the 12,24 and 48 -h hypoxia-treated cells. The fold change in target gene expression normalized to endogenous housekeeping gene and relative to aerobic control was quantified using the $2^{-\Delta \Delta C \mathrm{C}}$ method (35).

Mining the mutation status of isocitrate dehydrogenase (IDH) in GBM cell lines. The open access 'DepMap' portal of the Broad Institute (https://depmap.org/portal/) (36) was used to check for any identified somatic mutations in IDH1/2 in the cell lines used in the present study. The search results can be retrieved online for the M059J cell line (DepMap ID no. ACH-001118) and for the M059K cell line (DepMap ID no. ACH-000152).

Hypoxia labeling of tumor xenografts. Sections used in this study of ectopically-induced glioma tissue from mice injected with M006xLo cells were archived samples generated during a previous study published in 1998 (6). All previous animal experimentation was reviewed and approved by the Animal Care Committee at the Cross Cancer Institute in accordance with guidelines established by the Canadian Council for Animal Care. Briefly, the tumor tissues were initially obtained from tumor xenografts initiated in NOD/SCID mice at 6-10 weeks of age, when $10^{6}-10^{7}$ tumor cells were injected intradermally into both flanks of mice. When the tumor volumes reached $100-300 \mathrm{~mm}^{3}$, mice received a single intraperitoneal injection of the hypoxia marker, pimonidazole $\mathrm{HCl}$ (100 mg/kg; Natural Pharmacia International). Mice were euthanized 90 min later, and tumor xenografts were excised, fixed in buffered formalin (24-48 $\mathrm{h}$ at room temperature), embedded in paraffin and then sectioned at $5-\mu \mathrm{m}$ intervals. The M006xLo cell line used for these experiments has been extensively characterized with respect to its hypoxia-tolerant phenotype $(5-7,29)$ and produces xenografted tumors that are consistent in growth rate.

Tumor tissue immunostaining. Pimonidazole adducts were detected as previously described (37) with modifications. Xenograft slides were incubated in a dry oven at $62^{\circ} \mathrm{C}$ for $2 \mathrm{~h}$, deparaffinized, rehydrated and washed twice with $\mathrm{ddH}_{2} \mathrm{O}$ ( 2 min each), and then antigen retrieval was carried out using a Bio SB TintoRetrieval Pressure Cooker (Bio SB, Inc.) at high pressure for $15 \mathrm{~min}$. Xenograft slides were washed, endogenous peroxidase activity was blocked with Dako REAL peroxidase blocking buffer (cat. no. S2023; Dako; Agilent Technologies, Inc.) for $5 \mathrm{~min}$ at room temperature and then washed twice. Tissue sections were blocked for $30 \mathrm{~min}$ at room temperature with diluted 5\% normal goat serum (cat. no. ES 1028; Biomeda Corporation). Tissue sections were incubated for $1 \mathrm{~h}$ at room temperature with diluted (Dako Antibody Diluent; cat. no. S0809; Dako; Agilent Technologies, Inc.) rabbit primary antibodies against: Pimonidazole (1:200; cat. no. PAB2627AP; Hypoxyprobe, Inc.), MB (1:100; cat. no. ab77232; Abcam), CAIX (1:150; cat. no. 5648; Cell Signaling Technology, Inc.), LDHA (1:100; cat. no. 3582; Cell Signaling Technology, Inc.) or VEGF (1:100; cat. no. sc-507; Santa Cruz Biotechnology, Inc.). Negative controls of tissue sections were incubated without primary antibody. Tissue sections were washed twice with PBS (cat. no. 18912-014; Gibco; Thermo Fisher Scientific, Inc.) for $5 \mathrm{~min}$ each at room temperature, and then incubated with horseradish peroxidase-conjugated goat anti-rabbit immunoglobulin (Dako EnVision ${ }^{+}$; cat. no. K4002; Dako; Agilent Technologies, Inc.), and then Liquid DAB+ 2-Component system (cat. no. K3467; Dako; Agilent Technologies, Inc.) was added. The reaction was stopped by placing xenograft slides in $\mathrm{ddH}_{2} \mathrm{O}$. Slides were counterstained with Mayer's hematoxylin (cat. no. S3309; Dako; Agilent Technologies, Inc.) for $30 \mathrm{sec}$ at room temperature and then rinsed in $\mathrm{ddH}_{2} \mathrm{O}$. Slides were placed in lithium carbonate (cat. no. 62470-100G-F; Sigma-Aldrich; Merck KGaA) for $1 \mathrm{~min}$, washed and dehydrated, and then coverslips were mounted with Dako Ultramount Aqueous Permanent Mounting Medium (cat. no. S1964; Dako; Agilent Technologies, Inc.).

For slides stained with hematoxylin and eosin, slides were stained with eosin (cat. no. RRBD92-W; Atom Scientific Ltd.) for $2 \mathrm{~min}$ at room temperature after hematoxylin staining prior to the dehydration step.

Evaluation of slides was performed by two pathologists, with $\geq 5$ fields analyzed per sample. Photomicrographs were obtained at x10 and x40 magnification (Axio Scope.A1; Carl Zeiss AG)

Statistical analysis. Data are expressed as the mean \pm SE of four replicate experiments. Statistical analyses were performed using SigmaPlot 13 software (Systat Software Inc.). Differences between groups were assessed using one-way ANOVA followed by Dunnett's test for multiple comparisons with the control group. Additionally, Spearman rank correlation analysis was used to assess the relationship between MB expression and different hypoxia markers. The level of significance was set at $\mathrm{P}<0.05$.

\section{Results}

Expression of the protein-coding MB $m R N A$ splice variants 2, 9,10,11 and 13 in the M006xLo cell line. Amplified RT-PCR products separated on agarose gels showed clear bands that matched their predicted amplicon size (Fig. 1). Sequences analysis of the DNA extracted from agarose bands using 
the NBCI BLAST engine revealed perfect alignments to the corresponding mRNA sequences for the MB variants 2, 9, 10, 11 and 13 (Table SIII).

Quantification of the protein-coding MB mRNA splice variants 2, 9, 10, 11 and 13 in GBM cell lines under normoxic and hypoxic conditions. Hypoxia-sensitive (M059J, M010b) and hypoxia-tolerant (M059K, M006xLo) human GBM cell lines (5,29-31) were used for these experiments. Transcripts of all tested MB variants (Fig. 2A-E) were detected in all of the investigated cells, with the exception of MB muscle-type variant 2 transcript, which was not detected in M010b cells under either normoxic or hypoxic conditions. However, interestingly, this variant was downregulated by $\sim 46 \%$ in the M059J cell line as early as $12 \mathrm{~h}$ after exposure to hypoxia (Fig. 2A). A non-significant trend towards a reduction $(\sim 60 \%)$ of variant 2 mRNA was observed in the hypoxia-tolerant M006xLo cell at $24 \mathrm{~h}(\mathrm{P}=0.053)$ and $48 \mathrm{~h}(\mathrm{P}=0.053)$ of hypoxia, with its expression in M059K being not significantly altered in response to hypoxia (Fig. 2A). Significant upregulation (3-fold) of MB variant 9 was observed in M059K at $48 \mathrm{~h}$ of hypoxia, with a trend toward increased expression being also observed at $24 \mathrm{~h}$ (2.3-fold; $\mathrm{P}=0.085$; Fig. 2B). No significant changes in variant 9 gene expression were observed in the rest of the tested GBM cell lines. MB variants 10, 11 and 13 showed trends of increased expression under hypoxia (Fig. 2C-E). It is worth mentioning that the expression of these variants was previously shown to be induced by hypoxia in MDA-MB-468 and DLD-1 cell lines (19). However, in contrast to the range of durations of hypoxia employed here, the previous study assessed the hypoxic response of these variants only after $72 \mathrm{~h}$ of hypoxia.

Quantification of hypoxia markers in GBM cell lines. Hypoxia markers (LDHA, GLUT1, VEGF, and CAIX) were expressed in all cell lines (Fig. 2F-I) under normoxic conditions. Under hypoxic conditions, LDHA mRNA levels were significantly $(\mathrm{P}<0.05)$ upregulated at 12,24 and $48 \mathrm{~h}$ (M010b and M006xLo), at $48 \mathrm{~h}$ (M059J), or at 24 and $48 \mathrm{~h}(\mathrm{M} 059 \mathrm{~K})$ in the different cell lines (Fig. 2F). GLUT1 mRNA levels exhibited 2.5-11.9-fold increases in all cell lines, and were significantly increased $(\mathrm{P}<0.05)$ at $24 \mathrm{~h}$ in M059K cells, and at $48 \mathrm{~h}$ in M010b, M059J and M006xLo cells (Fig. 2G). VEGF mRNA showed significant increases $(\mathrm{P}<0.05)$ at $12 \mathrm{~h}(\mathrm{M} 006 \mathrm{xLo}), 24 \mathrm{~h}(\mathrm{M} 010 \mathrm{~b})$ or $48 \mathrm{~h}$ (M010b, M059J and M059K) in different cells lines; however, the 3.2-6.9-fold upregulation at other time points was not statistically significant (Fig. 2H). Hypoxic upregulation of CAIX mRNA levels ranged from 19- to 579-fold; significant increases were observed at $24 \mathrm{~h}$ in M059K and M006xLo cells, and at $48 \mathrm{~h}$ in all four cell lines (Fig. 2I). As there were no specific differences in the manner that hypoxia markers were altered in hypoxia-sensitive (M010b and M059J) compared with hypoxia-tolerant (M006xLo and M059K) GBM cells, it can be concluded that early hypoxia defensive mechanisms may be similar across these cell lines.

Correlation between protein-coding MB $m R N A$ variants and hypoxia markers in GBM cell lines. To further characterize the effects of hypoxia on the expression of MB variants, Spearman rank-order correlation analysis was performed; the correlation coefficients and corresponding P-values were calculated (Table I). MB variant 2 expression exhibited significant moderate-to-strong negative correlation with all of the tested hypoxia markers in M059J and M006xLo cells, with a trend of weak negative correlation with GLUT1 and CAIX also observed in M059K. Positive correlations between MB variant 9 and nearly all of the tested hypoxia markers were observed in the tested cells, with strong $(r \geq 0.785)$ and significant $\left(\mathrm{P}<10^{-6}\right)$ correlations in M059K cell line suggesting that this variant may contribute to this cell line's survival under hypoxia. MB variant 10 and variant 11 gene expression did not correlate significantly with any of the tested hypoxia markers in M010b, M059K or M006xLo cells. In the M059J cell line, moderate significant negative correlations between MB variant 10 or MB variant 11, and GLUT1 and VEGF were observed, with a trend towards a weakly negative correlation between variant 10 and CAIX. This finding, although unexpected, is of potential interest, as it indicates that hypoxia may negatively impact MB cancer-related variants, 10 and 11, in that particular cell line, which may potentially contribute to this cell line's vulnerability to hypoxic conditions. As for MB variant 13 , moderate borderline significant correlation with LDHA was observed in M010b, with no association detected with any of the tested hypoxia markers in M006xLo cell lines. In M059J and M059K cell lines, moderate-strong positive correlations between MB variant 13 and all tested hypoxia markers were observed. Collectively, these findings indicate that variant 13 is regulated by hypoxia in M010b, M059J and M059K cell lines, and may provide a protective or survival advantage in these cell lines.

Mutation status of IDH in GBM cell lines. Mining the mutation status of IDH revealed no somatic mutations in IDH1/2 in M059J and M059K cell lines (data not shown) (36).

Expression of MB protein and hypoxia markers protein in GBM xenografts. To investigate whether the expression of MB is upregulated under physiologically relevant hypoxic conditions that mimic the tumor microenvironment in patients with GBM, tumor xenografts were developed in NOD/SCID mice using M006xLo cells. Serial tumor sections were immunostained with antibodies specific for MB, and hypoxia markers LDHA, VEGF, GLUT1, CAIX and pimonidazole. In tumor sections, distinct regions of necrosis were used as landmarks to compare serial tumor sections. Tumor cells adjacent to necrotic areas were hypoxic, as shown by positive pimonidazole staining (Fig. 3). Similar patterns of staining with various degrees of immunoreactivity were shown in matched tumor regions adjacent to necrosis that were stained for $\mathrm{MB}$, CAIX, LDHA and VEGF. Other area of xenograft sections that lacked pimonidazole staining exhibited weak staining for MB and other hypoxia markers. These parts may represent well-oxygenated areas. These results indicating the presence of an association between the expression of MB and hypoxia marker proteins in xenografts generated using M006xLo cells contrast with in vitro results reporting a trend towards a reduction of variant 2 mRNA, and a lack of correlation between cancer-related MB variants and hypoxia markers in M006xLo cells. It should be noted that the xenograft tissues used in the present study were archived samples obtained during a 
Table I. Spearman rank correlation analysis of correlations between protein-coding MB mRNA variants and hypoxia markers in GBM cell lines.

\begin{tabular}{lllllll}
\hline \multirow{2}{*}{ Cell line } & & \multicolumn{5}{c}{ MB variant } \\
\cline { 3 - 7 } M010B & Marker & V2 & V9 & V10 & V11 & V13 \\
& LDHA & NA & $0.522^{\mathrm{a}}$ & 0.107 & 0.388 & $0.501^{\mathrm{a}}$ \\
& GLUT1 & NA & 0.310 & 0.200 & 0.233 & 0.233 \\
& VEGF & NA & 0.0776 & 0.0836 & -0.0687 & 0.257 \\
M059J & CAIX & NA & 0.164 & 0.0836 & -0.0328 & 0.418 \\
& LDHA & $-0.603^{\mathrm{a}}$ & 0.218 & -0.358 & -0.251 & $0.693^{\mathrm{a}}$ \\
& GLUT1 & $-0.788^{\mathrm{c}}$ & 0.191 & $-0.642^{\mathrm{b}}$ & $-0.555^{\mathrm{a}}$ & $0.567^{\mathrm{a}}$ \\
& VEGF & $-0.809^{\mathrm{c}}$ & 0.179 & $-0.713^{\mathrm{b}}$ & $-0.582^{\mathrm{a}}$ & $0.540^{\mathrm{a}}$ \\
M059K & CAIX & $-0.579^{\mathrm{a}}$ & 0.460 & -0.424 & -0.397 & $0.690^{\mathrm{b}}$ \\
& LDHA & -0.304 & $0.848^{\mathrm{c}}$ & 0.254 & 0.275 & $0.734^{\mathrm{c}}$ \\
& GLUT1 & -0.424 & $0.875^{\mathrm{c}}$ & 0.266 & 0.119 & $0.618^{\mathrm{a}}$ \\
& VEGF & -0.343 & $0.785^{\mathrm{c}}$ & 0.221 & 0.0507 & $0.696^{\mathrm{b}}$ \\
\multirow{3}{*}{ M006xLo } & CAIX & -0.430 & $0.845^{\mathrm{c}}$ & 0.0896 & 0.0328 & $0.696^{\mathrm{b}}$ \\
& LDHA & $-0.615^{\mathrm{a}}$ & -0.122 & -0.266 & -0.296 & -0.158 \\
& GLUT1 & $-0.698^{\mathrm{b}}$ & 0.131 & -0.0776 & -0.179 & 0.0209 \\
& VEGF & $-0.567^{\mathrm{a}}$ & -0.0985 & -0.212 & -0.230 & 0.0119 \\
& CAIX & $-0.738^{\mathrm{b}}$ & 0.119 & -0.119 & -0.397 & -0.227
\end{tabular}

${ }^{\mathrm{a}} \mathrm{P}<0.05 ;{ }^{\mathrm{b}} \mathrm{P}<0.01 ;{ }^{\mathrm{c}} \mathrm{P}<0.001$. Correlation between the protein-coding MB mRNA variants $2,9,10,11$ and 13 , and hypoxia markers in glioblastoma multiforme cell lines. Spearman rank-order correlation coefficients are presented; superscript letters indicate significant correlations. MB, myoglobin; LDHA, lactate dehydrogenase A; GLUT1, glucose transporter 1; VEGF, vascular endothelial growth factor; CAIX, carbonic anhydrase IX.

previous study (6). However, in a study investigating antigen preservation in formalin-fixed, paraffin-embedded blocks dating from several previous decades, it was concluded that antigenicity is maintained in FFPE material for $>60$ years (38), indicating that the results in the present study accurately reflect the expression of globins and pimonidazole-protein adducts in these cells.

\section{Discussion}

The aim of the present study was to investigate whether MB is expressed in GBM cells and, if so, whether its expression is modulated by hypoxia levels that simulate the hypoxic tumor microenvironment. Both standard and alternative cancer-associated MB variants have been reported be expressed in cancer tissue and cell lines, as well as in healthy breast, skeletal and heart muscle $(19,21)$. Our previous studies demonstrated that GBM ectopically expresses three of the globin family members; $\mathrm{Ngb}, \mathrm{Cygb}$ and $\mathrm{Hb}$, and that these oxygen-binding molecules are upregulated under hypoxic conditions $(3,9-11)$. These observations potentially explain the ability of GBM to grow and progress under hypoxia, as well as suggesting a reason for the poor prognosis and frequent recurrence associated with these cancers. In the present study, it was reported that different variants of another member of the globin family, MB, are ectopically expressed in four GBM cell lines (M010b, M059J, M059K and M006xLo). The cellular responses of these cell lines to hypoxia have been characterized previously. In contrast to hypoxia-sensitive and radiosensitive (M010b and M059J) cells (29,30), M059K and M006xLo cells are hypoxia-tolerant and radioresistant $(5,31,39)$.

It was found that the MB transcripts 9, 10, 11 and 13, and the standard MB transcript (variant 2) were expressed in the four cell lines, except for MB variant 2, which was undetectable in M010b. This observation is consistent with those of Kristiansen et al (27), who reported that MB was not detected in all cells of a breast cancer cell panel. Under hypoxia, hypoxia inducible factors (HIFs) orchestrate various cellular responses by binding to the hypoxia responsive elements (HREs) in their target genes (40). This induces the transcription of genes required for metabolic adaptations to $\mathrm{O}_{2}$ deficiency and glucose uptake (such as LDHA and GLUT1), tumor growth and metastasis (VEGF) and intracellular regulation of $\mathrm{pH}$ to maintain a relatively acidic $\mathrm{pH}$ extracellularly (CAIX), conditions that are compatible with cell viability and proliferation, as well as invasion and metastasis (40-44).

It was shown earlier that GBM cells modify oxygen consumption rates in response to variations in oxygen supply, which may contribute to GBM survival in hypoxic microenvironments (5). The ability to modify oxygen consumption differs among GBM cells; the hypoxia-tolerant M006x and M059K cell lines have the ability to lower oxygen utilization rates, whereas the hypoxia-sensitive M010b cell line does not. Consequently, and in contrast to the hypoxia-tolerant cell line M006, the M010b cell line significantly loses its 

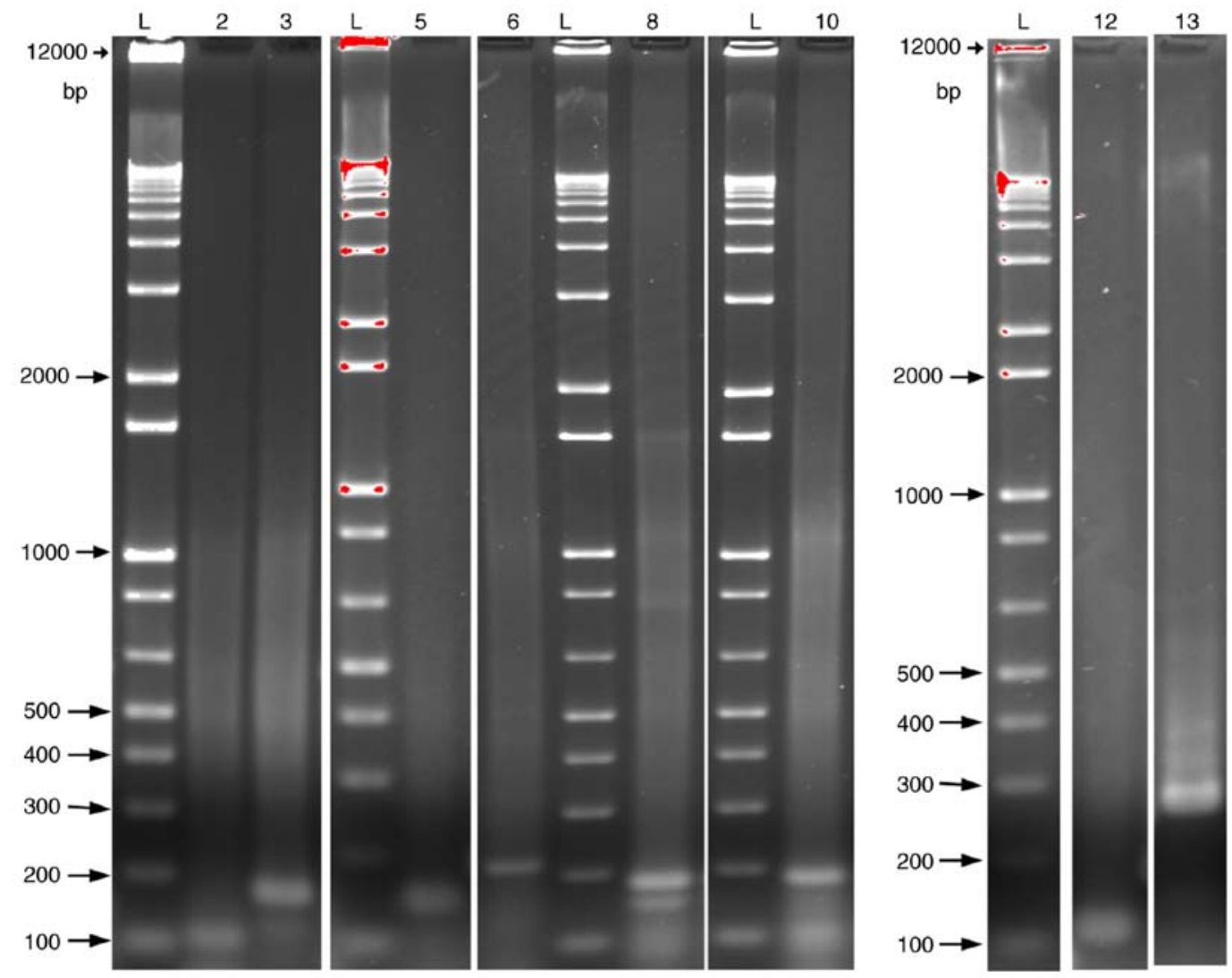

Figure 1. Protein-coding MB mRNA variant (2, 9, 10, 11 and 13) expression in M006xLo cells. Amplified reverse transcription-PCR products formed using specific sequence primer pairs were separated on $2 \%$ agarose gels and visualized using ethidium bromide. The amplicons of the predicted size were confirmed by DNA sequencing. Lanes: 2, MB (111 bp); 3, MB (179 bp); 5, MB variant 2 (151 bp); 6, MB variant 2 (219 bp); 8, MB variant 9 (189 bp); 10 , MB variant 10 (188 bp); 12, MB variant 11 (121 bp); 13, MB variant 13 (275 bp). For MB and variant 2, two primer pairs were used to confirm their presence. L, DNA ladder; MB, myoglobin.

colony-forming ability when maintained under hypoxia (5). In the present study, it was shown that hypoxia-tolerant and hypoxia-sensitive GBM cell lines are indeed hypoxia-responsive; hypoxia markers, including LDHA, GLUT1, VEGF and CAIX, were upregulated in the four tested cell lines under hypoxia. Thus, differences in their susceptibility to low oxygen tension cannot be explained solely on the basis of differential recruitment of any of the hypoxia responsive genes discussed above.

In the present study, MB variant 2 exhibited modestly negative significant correlations with hypoxia markers. In spite of the absence of canonical binding sites for the hypoxia-responsive master transcription factors HIF- $1 \alpha /-2 \alpha$ in its promoter $(45,46), \mathrm{MB}$ variant 2 was significantly increased in MDA-MB-468 breast cancer cells, but not DLD-1 colon cancer cells, following $72 \mathrm{~h}$ of $1 \% \mathrm{O}_{2}(19)$. This variation in variant 2 hypoxia responses (downregulation, upregulation or no change) underlines the complexity of cellar responses to hypoxia in different cell lines of different tumor origins that may reflect differential regulation of $\mathrm{MB}$ variant 2 . On the other hand, the expression of the MB cancer-associated variants $9,10,11$ and 13 collectively exhibited trends towards increased expression that were consistent with previous reports linking this upregulation with an HRE candidate within the upstream region of the MB gene, along with other, thus far uncharacterized, enhancer sites $(19,32)$.
Cell line-dependent changes in cancer-related MB variant gene expression are also apparent. For example, while a modest increase in MB variant 13 coupled with significant positive correlations with hypoxia markers was observed in hypoxia-sensitive (M010b and M059J) and hypoxia-tolerant cells (M059K), this variant was essentially unaltered and did not correlate with any of the tested markers of hypoxia in the M006xLo cell line. Also, while hypoxia appeared to positively regulate variants 9 and 13 in the M059K cell line, as indicated by the significant positive correlations with tested hypoxia markers, it had no effect on these variants in the other hypoxia-tolerant cell line, M006xLo. These results are similar to previously reported observations, where MB variant 13 was significantly upregulated in MDA-MB-468 breast cancer cells but not colon-derived DLD-1 subjected to $72 \mathrm{~h}$ at $0.6 \% \mathrm{O}_{2}(19,32)$. Similarly, the present data indicated that low oxygen tension downregulated variants 10 and 11 in the M059J cell line, as indicated by the significant negative correlation with markers of hypoxia; however, it had no effect on these variants in the M059K cell line.

Of the four-tested GBM cell lines, the M059K cell line showed the strongest association between variants 9 or 13, and each of the tested hypoxia markers. These associations potentially suggested that variant 9 and 13 confer some survival advantage in M059K cells under hypoxia, and thus may be responsible, at least in part, for the hypoxia-tolerant phenotype of this cell line. In contrast to M059K, the other hypoxia-tolerant cell line, M006xLo, appeared to not rely on 
A

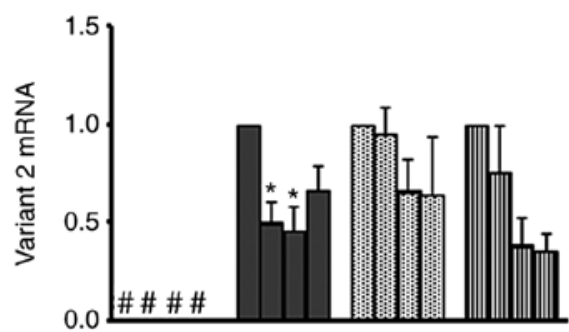

B
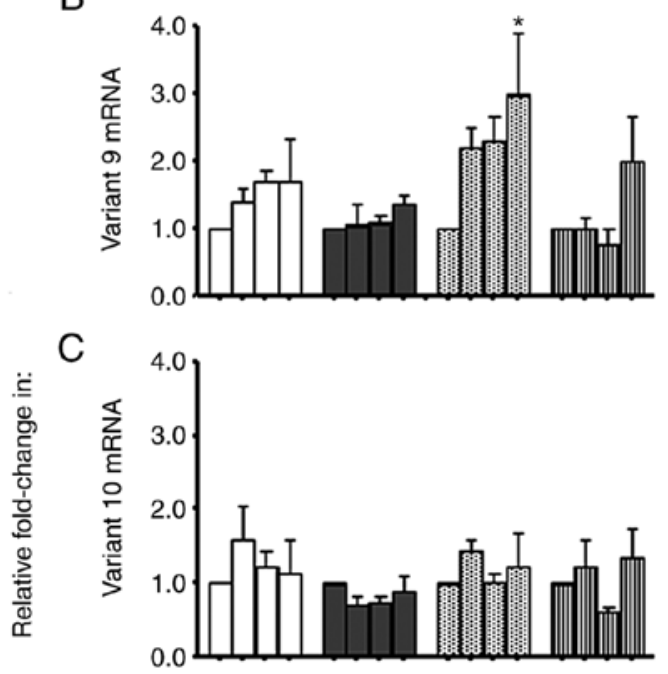

D

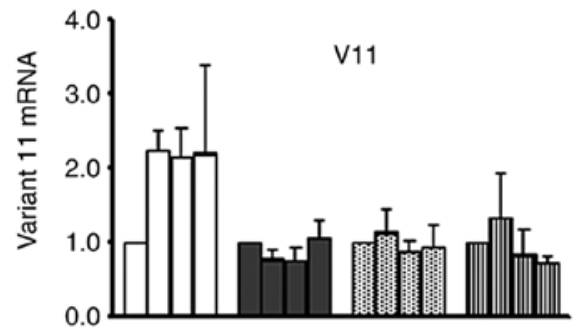

E

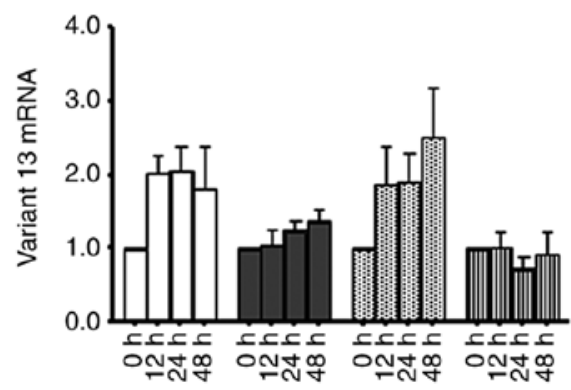

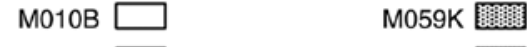

M006xLo [س]
F

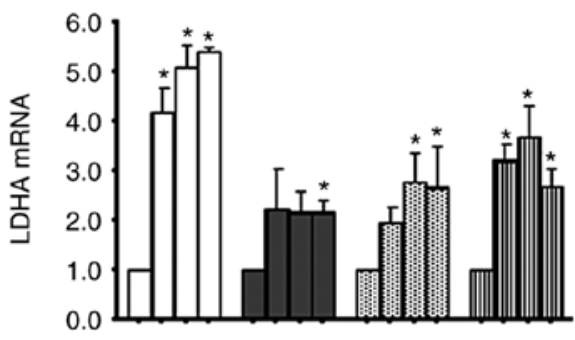

G

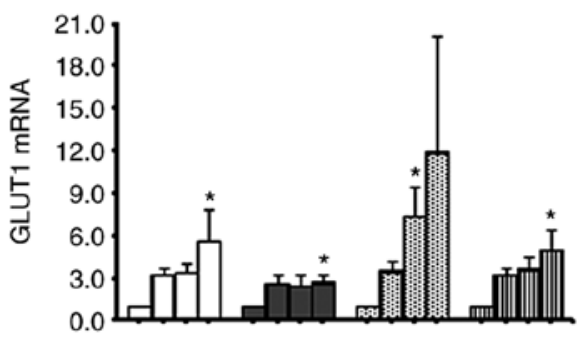

$\mathrm{H}$
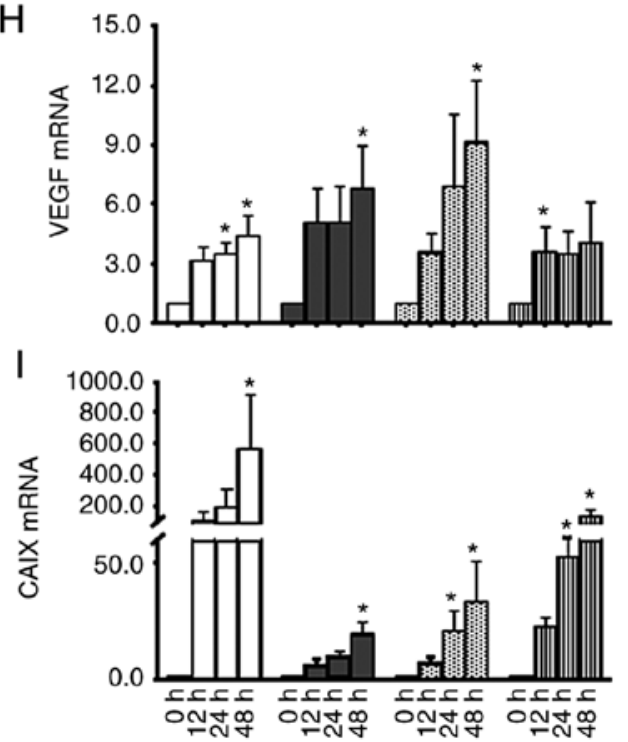

Figure 2. Expression of protein-coding MB mRNA splice variants in human GBM cell lines. Expression levels of (A) MB variant 2, (B) variant 9, (C) variant 10, (D) variant 11 and (E) variant 13, as well as the hypoxia markers (F) LDHA, (G) GLUT1, (H) VEGF and (I) CAIX were assessed in the human GBM cell lines, M010b, M059J, M059K and M06xLo, following exposure to hypoxia $\left(0.6 \% \mathrm{O}_{2}\right)$ for 0 (aerobic control), 12,24 and 48 h. Expression was analyzed via reverse transcription-quantitative $\mathrm{PCR}$, and data were expressed as fold increases relative to the aerobic control (n=4). $\mathrm{P}<0.05$ vs. $0 \mathrm{~h}$. \#, MB variant 2 was not detectable in M010b cells; MB, myoglobin; GBM, glioblastoma multiforme; LDHA, lactate dehydrogenase A; GLUT1, glucose transporter 1; VEGF, vascular endothelial growth factor; CAIX, carbonic anhydrase IX.

any of the MB cancer-related variants to survive the hypoxic tumor environment. Earlier reports revealed that other hypoxia-defying globins were activated in that particular cell line, such as $\mathrm{Ngb}$ and $\mathrm{Cygb}$, in addition to angiogenic factors, such as matrix metalloproteinase (MMP)-2 and MMP-9 $(3,8,11)$. This suggests that activation of these globins and/or other non-globin-dependent survival pathways may be responsible for this cell line's hypoxia-tolerant phenotype. It is worth noting that $\mathrm{Ngb}$ and $\mathrm{Hb}$ were also expressed and upregulated under low-oxygen conditions in the M059K cell line $(9,11)$; therefore, they may also contribute to the hypoxia-tolerant status demonstrated by this cell line.

MB variant 13 activation, as indicated by the significant positive correlations with markers of hypoxia, in the hypoxia-sensitive GBM cell lines appear to be minor or ineffective, particularly in M010b, where a moderate correlation was only observed with LDHA. Even in the M059J cell line, where a moderate positive association was observed between 
A

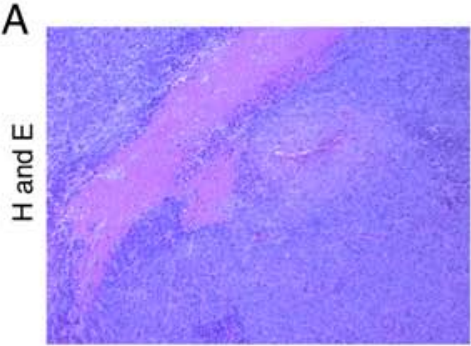

D

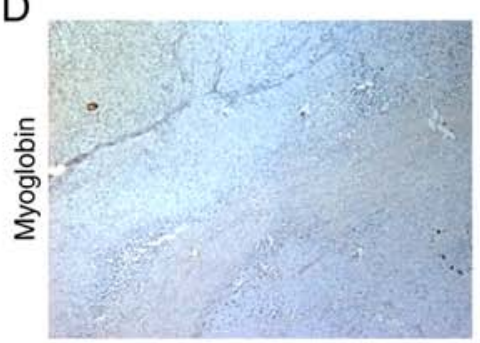

G
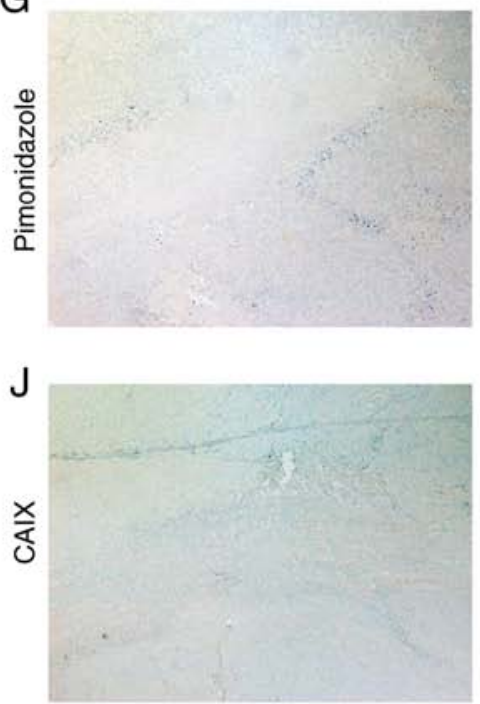

M

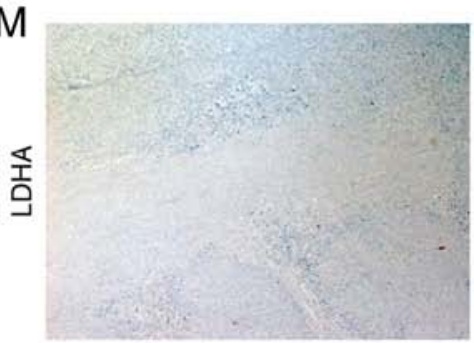

$P$

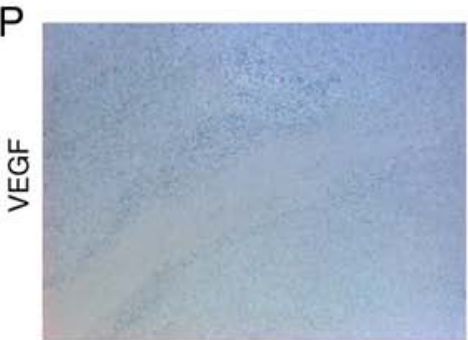

B

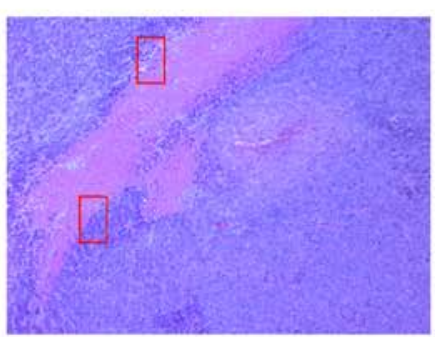

$\mathrm{E}$

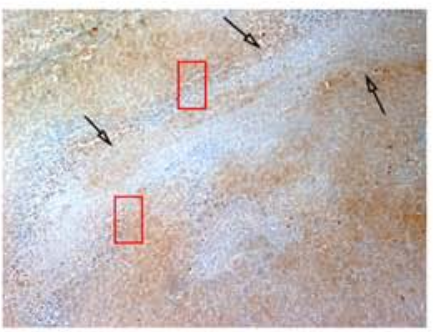

$\mathrm{H}$

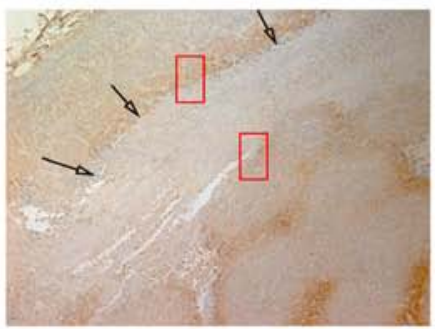

$\mathrm{K}$

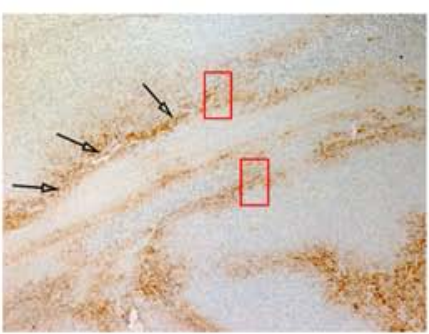

$\mathrm{N}$

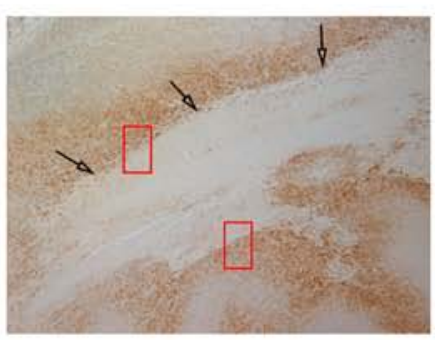

Q

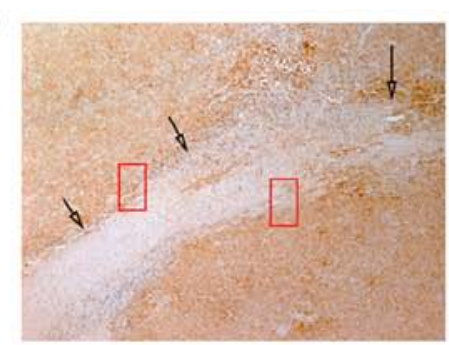

C

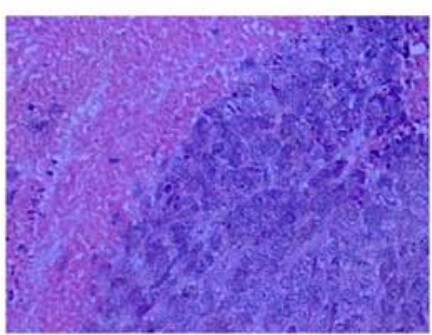

F

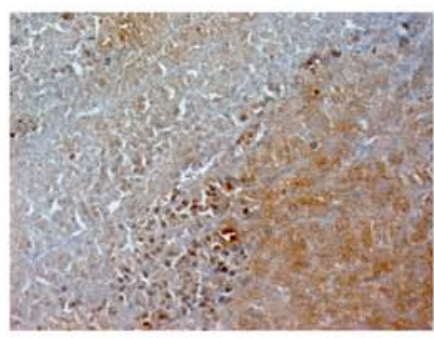

I

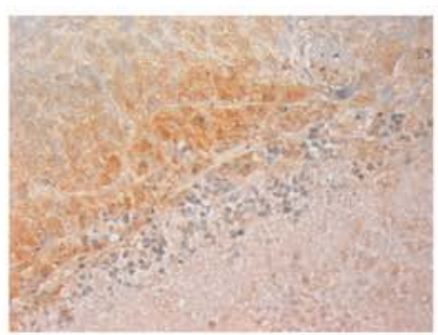

L

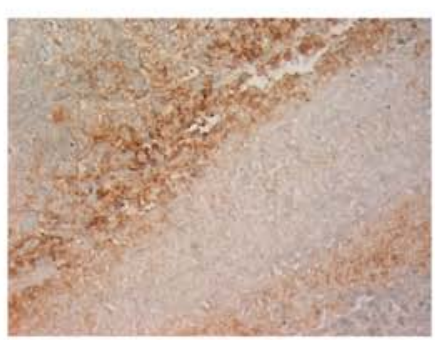

0

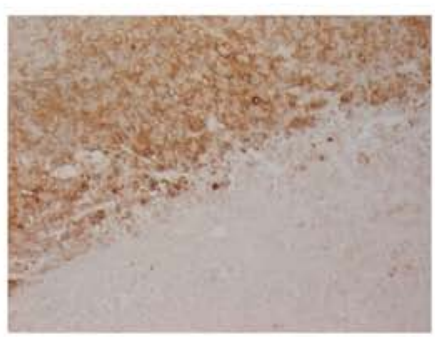

R

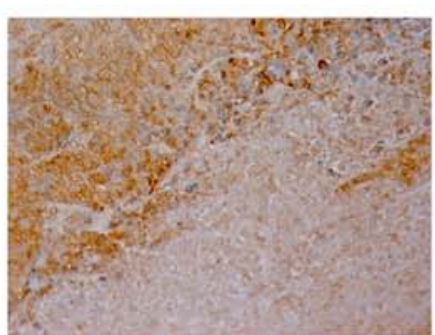

Figure 3. Expression of MB, CAIX, LDHA and VEGF in a M006xLo tumor xenograft. Ectopically-induced glioblastoma tumor xenografts in mice were generated via injection of M006xLo cells. Serial sections of tumor xenografts were stained with (A-C) H\&E, and antibodies specific for (D-F) MB, (G-I) pimonidazole, (J-L) CAIX, (M-O) LDHA and (P-R) VEGF. Regions of necrosis were used as tissue landmarks (red boxes). Hypoxic cells identified by pimonidazole staining also exhibited strong positive staining for MB, CAIX, LDHA and VEGF (black arrows). MB staining was weakly positive throughout other parts of tumor sections; however, these cells showed either weak or no staining for pimonidazole, CAIX, LDHA and VEGF. Image panels in the left column represent negative controls of tissue sections where, instead of primary antibody, slides were incubated with normal goat serum. Photomicrographs were obtained at x10 (left and middle panels) and x40 (right panels) magnification. 
variant 13 gene expression and each of the tested markers of hypoxia, one would expect that any role for variant 13 may be offset by the hypoxia-induced downregulation of the other cancer-related variants, 10 and 11 . It is worth mentioning that both of these cell lines express $\mathrm{Ngb}$ and Cygb (in addition to $\mathrm{Hb}$ in the M059K cell line), and their expression is upregulated by hypoxia $(3,9,11)$.

Thus far, it is not clear whether different members of the globin family interact and, if so, whether possible interactions may influence GBM cell hypoxia susceptibility. Future studies aiming to explore the cross-talk among different globins in hypoxia-sensitive and hypoxia-tolerant GBM cell lines should provide useful knowledge into the mechanisms of cancer cell survival under hypoxia. Further, exploring the contribution of different MB variants to GBM cell hypoxia sensitivity should provide insights into MB-dependent survival mechanisms.

Tumor xenografts established using the M006xLo cell line were used to investigate whether in vivo hypoxic conditions could enhance MB expression. The M006xLo cell line was selected as it displays a robust hypoxia-tolerant phenotype. Tumor-bearing mice received a single injection of pimonidazole $\mathrm{HCl} 90$ min prior to sacrificing. Pimonidazole is considered to be a gold standard for the assessment of tumor hypoxia (47), and in hypoxic cells (oxygen tensions $<10 \mathrm{mmHg}$ ), pimonidazole protein adducts are only detected following systemic administration (48). Co-staining of the cells adjacent to necrotic areas (using tissue landmarks) with pimonidazole and MB conformed to the classic model of hypoxia (49), and implied that in vivo MB expression may be regulated by oxygen-dependent mechanisms. Similar staining patterns for CAIX, LDHA and VEGF in serial sections of xenografts indicated that hypoxia is potentially involved in regulating $\mathrm{MB}$ expression in cancer tissues. Either MB variant 2, or MB cancer-related variants 9, 10, 11 and 13 encode the standard MB protein as found in muscle, where cancer-related variants are more strongly expressed (374-708-fold) compared with variant 2 (19). This suggests that expressed MB with a similar staining pattern to pimonidazole and other hypoxia markers is actually a translated protein of MB variants 9, 10, 11 or 13. The discrepancy between xenografts of M006xLo cells and in vitro culture of M006xLo cells in terms of the expression and association of MB protein and hypoxia markers could be explained by several factors. First, all MB transcript variants encode the same MB protein detected by MB antibody in the xenografts of M006xLo cells, which may indicate that MB expression in this cell line is determined by the contribution of multiple MB variants, rather than just one of them. Second, it was shown previously that the oxygen consumption rates of these glioma cells measured in vitro are poor predictors of changes likely to occur in vivo (5). Finally, the differences in nature between cell culture (in vitro) and cells in xenografts (in vivo) in terms of time ( $>2$ weeks is required to generate xenografts with volume of $200 \mathrm{~mm}^{3}$, compared with $48 \mathrm{~h}$ hypoxia in vitro, the maximum duration of hypoxia exposure of M006xLo cells in cell culture), and the varied severity of hypoxia in the tumor microenvironment in xenografts, as reflected by the distribution of pimonidazole staining, a widely accepted marker of tumor hypoxia in tumor speci- mens (50). These factors likely contributed to the differences in outcomes observed between cells and xenograft tissue. It should be noted that the lack of RNA interference and overexpression experiments in the studied glioma cell lines is a limitation of the present study; however, this issue is currently being addressed.

The MB pattern of expression in xenografts is similar to our previous observations with $\mathrm{Ngb}$, suggesting that $\mathrm{MB}$ and $\mathrm{Ngb}$ (and potentially other globins) are co-expressed in the same cells in hypoxic microregions of M006xLo-derived GBM tumor xenografts (9). It should be noted that neither heterotopic nor orthotopic xenograft models reflect the tumor microenvironment and cell fate of GBM in human patients. However, in the past 60 years, animal models have been used extensively to study brain tumors (51), due in part to the lack of perfect and reliable preclinical models (52). In the current study, mouse M006xLo xenograft tissue was solely used to confirm the associations between MB and hypoxia markers, which were observed in vitro using human GBM cell lines. Future work examining the co-expression of MB variants and hypoxia markers in other xenograft models (for example, using M059K or M010b cells) would be required to more fully understand the variation in expression from one tumor to another.

In previous studies, $\mathrm{MB}$ expression in a subset of invasive breast cancer cases correlated with HIF-2 $\alpha$ and CAIX, but not with HIF-1 $\alpha$ or GLUT1 (27), and breast ductal carcinoma in situ immunostaining of GLUT1 correlated with the degree of MB expression (32). In contrast, ectopic MB expression was significantly associated with overall survival in head and neck squamous cell carcinoma, and did not correlate with the hypoxia marker CAIX (18). Additionally, overexpression of MB using lentivirus prevented hypoxia in tumor cells, promoted differentiation and inhibited metastasis (53). These observations, and the very low level (several hundred-fold lower than in muscle tissue) of ectopically-expressed MB in healthy and tumorous tissues, and cancer cell lines (19), question its biological functions in this context. Apart from the effect of hypoxia on MB expression, chemically-induced oxidative stress ( $\mathrm{S}$-nitroso-N-acetylpenicillamine or $\mathrm{H}_{2} \mathrm{O}_{2}$ ) was also found to increase MB expression in MCF7 breast cancer cells (26).

According to the revised classification of tumors of the CNS by the World Health Organization, GBMs are divided into IDH mutant, wild-type or not otherwise specified (54). It is reported that $\sim 90 \%$ of GBMs are of a primary origin, whereas the rest represent secondary GBM that progresses from low-grade diffuse astrocytoma or anaplastic astrocytoma (55). Mutations in IDH were found in $<10 \%$ of primary glioblastomas (IDH wild-type tumors constitute $\sim 90 \%$ of cases), as well as $\sim 80 \%$ of grade II and III oligodendrogliomas, astrocytomas and secondary glioblastomas (56). Patients with glioblastoma carrying mutations in IDH exhibit an improved prognosis reflected by longer median overall survival associated with these tumors (54). To put the present findings into a clinically relevant perspective, DepMap was used to check for IDH1/2 mutations in the cell lines used in the present study (36). IDH1/2 mutations were not among the mutations reported in the M059J and M059K cell lines, suggesting that they carry the wild-type gene. No data on the other two cell 
lines, M010b and M006XLo, were found; however, in future studies, they will be checked for IDH1/2 mutations via DNA sequencing to analyze their characteristics from a clinical perspective.

Finally, it is worth noting that the ability of a cell to cope with decreased oxygen tension is not dependent on a single set of genes. Different genes involved in cell growth and death, and lipid metabolism, including insulin-like growth factor-1 receptor, fatty acid synthase, sterol regulatory element-binding protein-1c and programmed cell death protein-1/programmed death-ligand 1 , have been shown to contribute significantly to cancer cell hypoxia adaptation (57-59). Therefore, differences among the tested GBM cell lines in terms of their reliance on MB for hypoxia adaptation are not unexpected, and highlight the overwhelming complexity of these heterogeneous cancers.

In summary, it was shown for the first time, to our knowledge, that in GBM cells, MB cancer-associated variants are expressed under normoxic and hypoxic conditions, and exhibit modest-to-strong correlations with hypoxia markers at different time points following exposure to physiologically relevant $\mathrm{O}_{2}$ tension. In addition, in xenografts, $\mathrm{MB}$ protein exhibited staining patterns that were similar to hypoxia markers. Therefore, ectopic expression of MB in GBM cells may be a part of cellular defense mechanisms used by GBM tumors to survive and adapt to the hypoxic tumor microenvironment, and consequently resist chemo- and radiotherapy treatments.

\section{Acknowledgements}

We thank Ms Maha Ahmed (Center for Aging and Associated Diseases, Helmy Institute for Medical Sciences, Zewail City of Science and Technology) for her administrative support.

\section{Funding}

This research was funded by Zewail City for Science and Technology (internal fund), and Science and Technology Development Fund of the Ministry of Scientific Research (grant. no. 12695).

\section{Availability of data and materials}

The datasets used and/or analyzed during the current study are available from the corresponding author on reasonable request.

\section{Authors' contributions}

RET and ME conceived of the study. RET, IE, MM, OH, JAT and ME performed experiments. MEE and ME analyzed the data. MEE and RE wrote the original draft. RET, MEE, IE, JAT, and ME reviewed and edited the manuscript. All authors read and approved the final manuscript.

\section{Ethics approval and consent to participate}

The present study used animal tissue obtained during a previous study that was approved by the Animal Care Committee at the Cross Cancer Institute.

\section{Patient consent for participation}

Not applicable.

\section{Competing interests}

The authors declare that they have no competing interests.

\section{References}

1. Batash R, Asna N, Schaffer P, Francis N and Schaffer M: Glioblastoma Multiforme, Diagnosis and Treatment; Recent Literature Review. Curr Med Chem 24: 3002-3009, 2017.

2. Pisapia DJ, Magge R and Ramakrishna R: Improved pathologic diagnosis-forecasting the future in glioblastoma. Front Neurol 8: 707, 2018.

3. Emara M, Turner AR and Allalunis-Turner J: Hypoxic regulation of cytoglobin and neuroglobin expression in human normal and tumor tissues. Cancer Cell Int 10: 33, 2010.

4. Harada H: How can we overcome tumor hypoxia in radiation therapy? J Radiat Res 52: 545-556, 2011.

5. Allalunis-Turner MJ, Franko AJ and Parliament MB: Modulation of oxygen consumption rate and vascular endothelial growth factor mRNA expression in human malignant glioma cells by hypoxia. Br J Cancer 80: 104-109, 1999.

6. Franko AJ, Parliament MB, Allalunis-Turner MJ and Wolokoff BG: Variable presence of hypoxia in M006 human glioma spheroids and in spheroids and xenografts of clonally derived sublines. Br J Cancer 78: 1261-1268, 1998.

7. Parliament MB, Franko AJ, Allalunis-Turner MJ, Mielke BW, Santos CL, Wolokoff BG and Mercer JR: Anomalous patterns of nitroimidazole binding adjacent to necrosis in human glioma xenografts: Possible role of decreased oxygen consumption. $\mathrm{Br}$ J Cancer 75: 311-318, 1997.

8. Emara $\mathrm{M}$ and Allalunis-Turner J: Effect of hypoxia on angiogenesis related factors in glioblastoma cells. Oncol Rep 31: 1947-1953, 2014.

9. Emara M, Salloum N and Allalunis-Turner J: Expression and hypoxic up-regulation of neuroglobin in human glioblastoma cells. Mol Oncol 3: 45-53, 2009.

10. Emara M, Turner AR and Allalunis-Turner J: Adult, embryonic and fetal hemoglobin are expressed in human glioblastoma cells. Int J Oncol 44: 514-520, 2014.

11. Emara M, Turner AR and Allalunis-Turner J: Hypoxia differentially upregulates the expression of embryonic, fetal and adult hemoglobin in human glioblastoma cells. Int J Oncol 44: 950-958, 2014.

12. Kendrew JC, Dickerson RE, Strandberg BE, Hart RG, DAVIES DR, Phillips DC and Shore VC: Structure of myoglobin: A three-dimensional Fourier synthesis at 2 A. resolution. Nature 185: 422-427, 1960.

13. Totzeck M, Hendgen-Cotta UB, Rammos C, Petrescu AM, Meyer C, Balzer J, Kelm M and Rassaf T: Assessment of the functional diversity of human myoglobin. Nitric Oxide 26: 211-216, 2012.

14. Xie LK and Yang SH: Brain globins in physiology and pathology. Med Gas Res 6: 154-163, 2016

15. Qiu Y, Sutton L and Riggs AF: Identification of myoglobin in human smooth muscle. J Biol Chem 273: 23426-23432, 1998.

16. Fraser J, de Mello LV, Ward D, Rees HH, Williams DR, Fang Y, Brass A, Gracey AY and Cossins AR: Hypoxia-inducible myoglobin expression in nonmuscle tissues. Proc Natl Acad Sci USA 103: 2977-2981, 2006.

17. Roesner A, Mitz SA, Hankeln T and Burmester T: Globins and hypoxia adaptation in the goldfish, Carassius auratus. FEBS J 275: 3633-3643, 2008.

18. Meller S, VAN Ellen A, Gevensleben H, Bicker A, Hankeln T, Gorr TA, Sailer V, Dröge F, Schröck F, Bootz F, et al: Ectopic myoglobin expression is associated with a favourable outcome in head and neck squamous cell carcinoma patients. Anticancer Res 36: 6235-6241, 2016.

19. Bicker A, Dietrich D, Gleixner E, Kristiansen G, Gorr TA and Hankeln T: Extensive transcriptional complexity during hypoxia-regulated expression of the myoglobin gene in cancer. Hum Mol Genet 23: 479-490, 2014. 
20. Meller S, Bicker A, Montani M, Ikenberg K, Rostamzadeh B, Sailer V, Wild P, Dietrich D, Uhl B, Sulser T, et al: Myoglobin expression in prostate cancer is correlated to androgen receptor expression and markers of tumor hypoxia. Virchows Arch 465: 419-427, 2014.

21. Bicker A, Brahmer AM, Meller S, Kristiansen G, Gorr TA and Hankeln T: The distinct gene regulatory network of myoglobin in prostate and breast cancer. PLoS One 10: e0142662, 2015.

22. Behnes CL, Bedke J, Schneider S, Küffer S, Strauss A, Bremmer F, Ströbel P and Radzun HJ: Myoglobin expression in renal cell carcinoma is regulated by hypoxia. Exp Mol Pathol 95: 307-312, 2013.

23. Oleksiewicz U, Daskoulidou N, Liloglou T, Tasopoulou K, Bryan J, Gosney JR, Field JK and Xinarianos G: Neuroglobin and myoglobin in non-small cell lung cancer: Expression, regulation and prognosis. Lung Cancer 74: 411-418, 2011.

24. Ruck P, Horny HP, Greschniok A, Wehrmann M and Kaiserling E: Nonspecific immunostaining of blast cells of acute leukemia by antibodies against nonhemopoietic antigens. Hematol Pathol 9 : 49-56, 1995.

25. Zhang PJ, Goldblum JR, Pawel BR, Fisher C, Pasha TL and Barr FG: Immunophenotype of desmoplastic small round cell tumors as detected in cases with EWS-WT1 gene fusion product. Mod Patho 16: 229-235, 2003.

26. Flonta SE, Arena S, Pisacane A, Michieli P and Bardelli A: Expression and functional regulation of myoglobin in epithelial cancers. Am J Pathol 175: 201-206, 2009.

27. Kristiansen G, Rose M, Geisler C, Fritzsche FR, Gerhardt J, Lüke C, Ladhoff AM, Knüchel R, Dietel M, Moch H, et al: Endogenous myoglobin in human breast cancer is a hallmark of luminal cancer phenotype. Br J Cancer 102: 1736-1745, 2010.

28. Allalunis-Turner MJ, Barron GM, Day RS III, Fulton DS and Urtasun RC: Radiosensitivity testing of human primary brain tumor specimens. Int J Radiat Oncol Biol Phys 23: 339-343, 1992

29. Turcotte ML, Parliament M, Franko A and Allalunis-Turner J. Variation in mitochondrial function in hypoxia-sensitive and hypoxia-tolerant human glioma cells. Br J Cancer 86: 619-624, 2002.

30. Catania A,Urban S, YanE,Hao C,Barron G and Allalunis-Turner J: Expression and localization of cyclin-dependent kinase 5 in apoptotic human glioma cells. Neuro Oncol 3: 89-98, 2001.

31. DeHaan C, Habibi-Nazhad B, Yan E, Salloum N, Parliament M and Allalunis-Turner J: Mutation in mitochondrial complex I ND6 subunit is associated with defective response to hypoxia in human glioma cells. Mol Cancer 3: 19, 2004.

32. Kristiansen G, Hu J, Wichmann D, Stiehl DP, Rose M, Gerhardt J, Bohnert A, ten Haaf A, Moch H, Raleigh J, et al: Endogenous myoglobin in breast cancer is hypoxia-inducible by alternative transcription and functions to impair mitochondrial activity: A role in tumor suppression? J Biol Chem 286: 43417-43428, 2011.

33. Altschul SF, Madden TL, Schaffer AA, Zhang J, Zhang Z, Miller W and Lipman DJ: Gapped BLAST and PSI-BLAST: A new generation of protein database search programs. Nucleic Acids Res 25: 3389-3402, 1997.

34. Koch CJ, Howell RL and Biaglow JE: Ascorbate anion potentiates cytotoxicity of nitro-aromatic compounds under hypoxic and anoxic conditions. Br J Cancer 39: 321-329, 1979.

35. Livak KJ and Schmittgen TD: Analysis of relative gene expression data using real-time quantitative PCR and the 2(-Delta Delta C(T)) method. Methods 25: 402-408, 2001

36. Ghandi M, Huang FW, Jane-Valbuena J, Kryukov GV, Lo CC, McDonald ER III, Barretina J, Gelfand ET, Bielski CM, Li H, et al: Next-generation characterization of the Cancer Cell Line Encyclopedia. Nature 569: 503-508, 2019.

37. Kleiter MM, Thrall DE, Malarkey DE, Ji X, Lee DY, Chou SC and Raleigh JA: A comparison of oral and intravenous pimonidazole in canine tumors using intravenous CCI-103F as a control hypoxia marker. Int J Radiat Oncol Biol Phys 64: 592-602, 2006.

38. Grillo F, Bruzzone M, Pigozzi S, Prosapio S, Migliora P, Fiocca R and Mastracci L: Immunohistochemistry on old archival paraffin blocks: Is there an expiry date? J Clin Pathol 70: 988-993, 2017.

39. Murray D, Mirzayans R, Scott AL and Allalunis-Turner MJ: Influence of oxygen on the radiosensitivity of human glioma cell lines. Am J Clin Oncol 26: e169-e177, 2003.
40. Dengler VL, Galbraith $\mathrm{M}$ and Espinosa JM: Transcriptional regulation by hypoxia inducible factors. Crit Rev Biochem Mol Biol 49: 1-15, 2014.

41. Kaluz S, Kaluzova M, Liao SY, Lerman M and Stanbridge EJ: Transcriptional control of the tumor- and hypoxia-marker carbonic anhydrase 9: A one transcription factor (HIF-1) show? Biochim Biophys Acta 1795: 162-172, 2009.

42. Cui XG, Han ZT, He SH, Wu XD, Chen TR, Shao $\mathrm{CH}$, Chen DL, Su N, Chen YM, Wang T, et al: HIF1/2 $\alpha$ mediates hypoxia-induced LDHA expression in human pancreatic cancer cells. Oncotarget 8: 24840-24852, 2017.

43. Turner KJ, Crew JP, Wykoff CC, Watson PH, Poulsom R, Pastorek J, Ratcliffe PJ, Cranston D and Harris AL: The hypoxia-inducible genes VEGF and CA9 are differentially regulated in superficial vs. invasive bladder cancer. $\mathrm{Br}$ J Cancer 86: 1276-1282, 2002.

44. Chiche J, Brahimi-Horn MC and Pouyssegur J: Tumour hypoxia induces a metabolic shift causing acidosis: A common feature in cancer. J Cell Mol Med 14: 771-794, 2010.

45. Kanatous SB, Mammen PP, Rosenberg PB, Martin CM, White MD, Dimaio JM, Huang G, Muallem S and Garry DJ: Hypoxia reprograms calcium signaling and regulates myoglobin expression. Am J Physiol Cell Physiol 296: C393-C402, 2009.

46. Wystub S, Ebner B, Fuchs C, Weich B, Burmester T and Hankeln T: Interspecies comparison of neuroglobin, cytoglobin and myoglobin: Sequence evolution and candidate regulatory elements. Cytogenet Genome Res 105: 65-78, 2004.

47. Tamaki $\mathrm{N}$ and Hirata K: Tumor hypoxia: A new PET imaging biomarker in clinical oncology. Int J Clin Oncol 21: 619-625, 2016.

48. Hirakawa Y, Tanaka T and Nangaku M: Renal Hypoxia in CKD; Pathophysiology and detecting methods. Front Physiol 8: 99, 2017.

49. Brown JM and Wilson WR: Exploiting tumour hypoxia in cancer treatment. Nat Rev Cancer 4: 437-447, 2004.

50. Ljungkvist AS, Bussink J, Kaanders JH and van der Kogel AJ: Dynamics of tumor hypoxia measured with bioreductive hypoxic cell markers. Radiat Res 167: 127-145, 2007.

51. Huszthy PC, Daphu I, Niclou SP, Stieber D, Nigro JM, Sakariassen PØ, Miletic H, Thorsen F and Bjerkvig R: In vivo models of primary brain tumors: Pitfalls and perspectives. Neuro Oncol 14: 979-993, 2012.

52. Patrizii M, Bartucci M, Pine SR and Sabaawy HE: Utility of glioblastoma patient-derived orthotopic xenografts in drug discovery and personalized therapy. Front Oncol 8: 23, 2018.

53. Galluzzo M, Pennacchietti S, Rosano S, Comoglio PM and Michieli P: Prevention of hypoxia by myoglobin expression in human tumor cells promotes differentiation and inhibits metastasis. J Clin Invest 119: 865-875, 2009.

54. Louis DN, Perry A, Reifenberger G, von Deimling A, Figarella-Branger D, Cavenee WK, Ohgaki H, Wiestler OD, Kleihues P and Ellison DW: The 2016 World Health Organization Classification of Tumors of the Central Nervous System: A summary. Acta Neuropathol 131: 803-820, 2016.

55. Huang J, Yu J, Tu L, Huang N, Li H and Luo Y: Isocitrate dehydrogenase mutations in glioma: From basic discovery to therapeutics development. Front Oncol 9: 506, 2019.

56. Megova M, Drabek J, Koudelakova V, Trojanec R, Kalita O and Hajduch M: Isocitrate dehydrogenase 1 and 2 mutations in gliomas. J Neurosci Res 92: 1611-1620, 2014.

57. Liu Q, Guan JZ, Sun Y, Le Z, Zhang P, Yu D and Liu Y: Insulin-like growth factor 1 receptor-mediated cell survival in hypoxia depends on the promotion of autophagy via suppression of the PI3K/Akt/mTOR signaling pathway. Mol Med Rep 15: 2136-2142, 2017.

58. Ezzeddini R, Taghikhani M, Somi MH, Samadi N and Rasaee MJ: Clinical importance of FASN in relation to HIF-1 $\alpha$ and SREBP-1c in gastric adenocarcinoma. Life Sci 224: 169-176, 2019.

59. Koh YW, Lee SJ, Han JH, Haam S, Jung J and Lee HW: PD-L1 protein expression in non-small-cell lung cancer and its relationship with the hypoxia-related signaling pathways: A study based on immunohistochemistry and RNA sequencing data. Lung Cancer 129: 41-47, 2019. 